Leukemia -Lymphoma and Myeloma

\title{
Primary Bone Lymphoma: An Experience of a Regional Cancer Center from India
}

\author{
Rohit Mahajan ${ }^{1}$ Budhi Singh Yadav ${ }^{2}$ Suresh Chander Sharma ${ }^{1}$ Ankita Gupta ${ }^{2}$ Shikhar Kumar ${ }^{2}$ \\ ${ }^{1}$ Department of Radiotherapy and Oncology, Maharishi \\ Markandeshwar Institute of Medical Sciences and Research, \\ Ambala, Haryana, India \\ ${ }^{2}$ Department of Radiotherapy and Oncology, Post Graduate

\begin{abstract}
Address for correspondence Budhi Singh Yadav, MD, Radiation Oncology, Department of Radiotherapy and Oncology, Post Graduate Institute of Medical Education and Research, Sector 12, Chandigarh 160012, India (e-mail: drbudhi@gmail.com).
\end{abstract} Institute of Medical Education and Research, Chandigarh, India

South Asian J Cancer 2021;9:227-229.

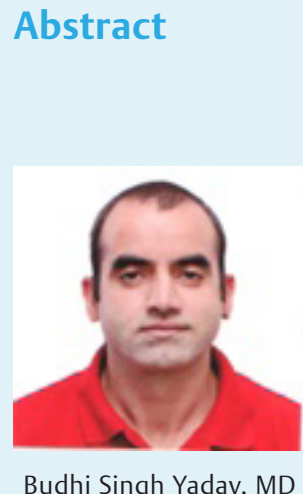

Keywords

- India

- NHL

- primary bone

lymphoma
Background Primary bone lymphoma (PBL) is a rare disease, representing $<5 \%$ of all extranodal non-Hodgkin's lymphomas (NHLs). The optimal treatment strategy is still unclear. Here, we report our institutional outcome analysis of patients diagnosed with PBL. Materials and Methods From 2007 to 2014, the medical records of 22 patients with PBL were reviewed. Analysis was done for symptom-, patient-, disease-, and treatment-related characteristics. All patients were treated with chemotherapy with or without radiotherapy. Treatment response and impact of different prognostic factors on clinical outcome were analyzed.

Results The median age of presentation was 44 years (range: $18-70$ years). A total of $19(86.4 \%)$ patients were $\leq 60$ years of age and $3(13.6 \%)$ patients were $>60$ years. Out of all, 18 were males and 4 were females. Ann Arbor clinical staging at diagnosis was Stage I in 13 (59.1\%), Stage II in 3 (13.6\%), Stage III in 2 (9.1\%), and Stage IV in 4 (18.2\%) patients. Spine was the most common site of involvement seen in $12(54.5 \%)$ patients. Diffuse large B cell lymphoma histology was seen in 8 (36.4\%) patients and 8 (36.4\%) had high-grade NHL. Chemotherapy with cyclophosphamide, doxorubicin, vincristine, and prednisolone was given to 20 (90.9\%) patients, whereas $2(9.1 \%)$ patients received cyclophosphamide, doxorubicin, vincristine, prednisone, and rituximab. Radiotherapy (30-40 Gy) was delivered to 19 (86.4\%) patients. The median follow-up period was 40 months (range: $8-105$ months). The overall response rate was $86.3 \%$ with complete response (CR) in $15(68.1 \%)$ and partial response in $4(18.2 \%)$ patients. Relapses were seen in three (13.5\%) patients: two nodal, and one in the bone. Disease-free survival (DFS) and overall survival (OS) at 5 years were 56.6 and $72.7 \%$, respectively. CR after initial treatment was associated with a significant better OS, 80 and $25 \%$, respectively $(p<0.0001)$. Age, sex, stage, International Prognostic Index, histologic subtype, and number of sites had no significant influence on OS. Combining radiation therapy with chemotherapy (with or without rituximab) also did not improve the OS or DFS of patients.

Conclusion In spite of small number of patients reported in this study, conventional chemotherapy remains an effective treatment option for patients with PBL. OS was found to be affected by the initial response to treatment.
DOI https://doi.org/10.1055/s-0040-1721173 ISSN 2278-330X.

How to cite this article: Mahajan R, Yadav B. S., Sharma S. C., Gupta A, Kumar S. Primary Bone Lymphoma: An Experience of a Regional Cancer Center from India. South Asian J Cancer 2021;9(4):227-229.
(C) 2020. MedIntel Services Pvt Ltd.

This is an open access article published by Thieme under the terms of the Creative Commons Attribution-NonDerivative-NonCommercial-License, permitting copying and reproduction so long as the original work is given appropriate credit. Contents may not be used for commercial purposes, or adapted, remixed, transformed or built upon. (https://creativecommons.org/licenses/by-nc-nd/4.0/)

Thieme Medical and Scientific Publishers Pvt. Ltd., A-12, 2nd Floor, Sector 2, Noida-201301 UP, India 


\section{Introduction}

Primary bone lymphoma (PBL) is a rare disease, representing $<5 \%$ of all extranodal non-Hodgkin's lymphomas (NHLs) and $<2 \%$ of all lymphomas in adults. ${ }^{1}$ The most common histopathological subtype of PBL is diffuse large B cell lymphoma (DLBCL). ${ }^{2}$ Standard treatment regimens have not yet been established because of the low incidence rates of PBL. PBL was initially treated with radiation therapy (RT) or surgery. After the introduction of cytotoxic agents as treatment options for PBL, several studies have established that chemotherapy combined with RT is better than RT alone. ${ }^{1,3}$ Many studies have shown that the addition of rituximab to chemotherapy regimens improves outcomes in patients with aggressive nonosseous NHL, whereas others have not shown additional benefits of supplementing chemotherapy with either rituximab or RT, ${ }^{4,5}$ Thus, optimal treatment strategy is still unclear. Here, we report our institutional outcome analysis of patients diagnosed with PBL.

\section{Materials and Methods}

From 2007 to 2014, the medical records of 22 patients with PBL (biopsy proven) were reviewed. A complete history was recorded and physical examination including local examination of disease. Baseline investigations such as complete blood count, blood biochemistry, chest X-rays, and bone marrow biopsy with histopathological examination were done. All patients underwent neck, chest, abdominal, and pelvic computed tomography (CT) scans or positron emission tomography (PET) scan. Staging was done with CT/PET scans. All patients were treated with chemotherapy with or without RT. Clinical features, treatment response, and impact of different prognostic factors on clinical outcome were analyzed.

Assessment of response to treatment was defined according to the international workshop criteria. ${ }^{6}$ Complete response (CR) was defined as disappearance of all detectable clinical and radiographic evidence of disease, excluding abnormalities attributed to bone remodeling. Partial response (PR) was defined as $\mathrm{a} \geq 50 \%$ reduction in all measurable tumors. Progressive disease (PD) was defined as a $\geq 50 \%$ in the size of previously involved sites or the appearance of new lesions despite treatment. Stable disease was defined as a response lesser than PR, but not fulfilling the PD criteria.

\section{Results}

The median age of presentation was 44 years (range: $18-70$ years). A total of 19 (86.4\%) patients were $\leq 60$ years of age and three (13.6\%) patients were of $>60$ years of age. Out of all, 18 were males and 4 were females. Ann Arbor clinical staging at diagnosis was Stage I in 13 (59.1\%), Stage II in 3 (13.6\%), Stage III in 2 (9.1\%), and Stage IV in $4(18.2 \%)$ patients (-Table 1$)$. Spine was the most common site of involvement seen in $12(54.5 \%)$ patients (-Table 2). DLBCL histology was seen in eight (36.4\%) patients and eight (36.4\%) patients had high-grade NHL. Chemotherapy with cyclophosphamide, doxorubicin,
Table 1 Patient characteristics

\begin{tabular}{|c|c|c|c|}
\hline Characteristics & & $\begin{array}{l}\text { Number } \\
\text { of } \\
\text { patients }\end{array}$ & Percentage \\
\hline \multirow[t]{2}{*}{ Age } & $<60$ & 19 & 86.4 \\
\hline & $>60$ & 3 & 13.6 \\
\hline \multirow[t]{2}{*}{ Sex } & Male & 18 & 81.8 \\
\hline & Female & 4 & 18.2 \\
\hline \multirow[t]{2}{*}{ B symptoms } & No & 70 & 94.6 \\
\hline & Yes & 4 & 5.4 \\
\hline \multirow[t]{3}{*}{ IPI } & Low & 7 & 31.8 \\
\hline & Low intermediate & 1 & 4.5 \\
\hline & Not defined & 14 & 63.6 \\
\hline \multirow[t]{4}{*}{ Stages } & 1 & 13 & 59.1 \\
\hline & II & 3 & 13.6 \\
\hline & III & 2 & 9.1 \\
\hline & IV & 4 & 18.2 \\
\hline \multirow[t]{2}{*}{ Number of sites } & Solitary & 17 & 77.3 \\
\hline & Multiple & 5 & 22.7 \\
\hline \multirow[t]{4}{*}{ Histology } & $\mathrm{NHL}-$ high grade & 8 & 36.4 \\
\hline & $\mathrm{NHL}$ & 5 & 22.7 \\
\hline & DLBCL & 8 & 36.4 \\
\hline & $\begin{array}{l}\text { Burkitt's } \\
\text { lymphoma }\end{array}$ & 1 & 4.5 \\
\hline \multirow[t]{2}{*}{ Treatment } & CCT & 3 & 13.6 \\
\hline & $C C T+R T$ & 19 & 86.4 \\
\hline \multirow[t]{2}{*}{ Chemotherapy } & $\mathrm{CHOP}$ & 20 & 90.9 \\
\hline & $\mathrm{R}-\mathrm{CHOP}$ & 2 & 9.1 \\
\hline
\end{tabular}

Abbreviations: $\mathrm{CCT}+\mathrm{RT}$, computed chemotherapy + radiotherapy; $\mathrm{CHOP}$, cyclophosphamide, doxorubicin, vincristine, and prednisolone; DLBCL, diffuse large B cell lymphoma; IPI, International Prognostic Index; NHL, non-Hodgkin's lymphoma; R-CHOP, cyclophosphamide, doxorubicin, vincristine, prednisone, and Rituxan.

Table 2 Bone sites

\begin{tabular}{|l|l|l|}
\hline Bone sites & Number of patients & Percentage \\
\hline Spine & 12 & 54.5 \\
\hline Femur & 2 & 9.1 \\
\hline Pelvic bone & 2 & 9.1 \\
\hline Ribs & 2 & 9.1 \\
\hline Humerus & 1 & 4.5 \\
\hline Tibia & 1 & 4.5 \\
\hline Skull & 1 & 4.5 \\
\hline Sternum & 1 & 4.5 \\
\hline
\end{tabular}

vincristine, and prednisolone was given to 20 (90.9\%) patients, whereas $2(9.1 \%)$ patients received cyclophosphamide, doxorubicin, vincristine, prednisone, and Rituxan, RT (30-40 Gy) was delivered to 19 (86.4\%) patients. Only two patients had Grade 3 hematological toxicity during chemotherapy, whereas in the rest, both chemotherapy and radiation treatment were tolerated well. The median follow-up period was 40 months (range: 8-105 months). The overall response rate was $86.3 \%$ with CR in 15 (68.1\%) and PR in 4 (18.2\%) patients. Relapses were seen in three 
(13.5\%) patients: two nodal, and one in the bone. Diseasefree survival (DFS) and overall survival (OS) at 5 years were 56.6 and $72.7 \%$, respectively. CR after initial treatment was associated with a significantly better OS, $80 \%$ versus $25 \%$, respectively $(p<0.0001)$. Age, sex, stage, International Prognostic Index (IPI), histologic subtype, and number of sites had no significant influence on OS. Combining RT with chemotherapy (with or without rituximab) also did not improve the OS or DFS of patients.

\section{Discussion}

PBL is a rare disease, and thus, conducting prospective studies is challenging and experience in the literature comes from small retrospective case series. In our series, DLBCL and high-grade NHL were the most common histopathologic subtypes in accordance with other series. ${ }^{7}$ NHL histology with grade not mentioned was also seen in five patients in our study.

Interestingly, the sites of occurrence differ among the various studies: in our study, predominance of axial involvement was seen; this was also seen in the Surveillance, Epidemiology, and End Results (SEER) database study, which reported a predominance of axial involvement among 1,500 PBL patients. ${ }^{8,9}$ Pelvis was the most common site seen in two series of Japanese patients, ${ }^{10,11}$ whereas in studies by Heyning et al and Zinzani et al, the most common sites of disease were the long bones. ${ }^{12,13}$ Another study of 131 patients of the British Columbia Cancer Agency reported equal frequency between axial and extremity involvement. $^{5}$

Combination chemotherapy results in durable responses, but no prospective randomized studies have been performed to optimize treatment strategies. Some studies have shown improved response and OS results in patients who received chemotherapy with RT. ${ }^{13,14}$ However, the study of the British Columbia Cancer Agency reported conflicting results. ${ }^{5}$ More recently, the introduction of the anti-CD20 monoclonal antibody rituximab has transformed the treatment of NHLs. In our study, combining RT with chemotherapy (with or without rituximab) also did not improve the OS or DFS of patients. A large number of small retrospective studies have reported conflicting results, as a result of which we are unable to conclude the effect of rituximab in the OS of PBL patients., ${ }^{4,515,16}$ In our study, the 5-year survival rate was $72.7 \%$, and we found that it was significantly affected by the initial response after first-line treatment $(p<0.0001)$. The reported 5-year survival rates vary greatly, from $60 \%$ for the patients diagnosed after 1996 in the SEER database study up to $95.2 \%$ in a series published by Pellegrini et al in 2011. ${ }^{8,16}$ Various studies have reported different prognostic factors, such as age,,$^{8,9}$ sex,,$^{15}$ stage, ${ }^{5}$ lactate dehydrogenase levels, ${ }^{14}$ IPI, ${ }^{5}$ histologic subtype, ${ }^{10}$ and number of bones involved, ${ }^{4}$ but in our study, none of these mentioned factors had any significant influence on OS. Retrospective nature and small number of patients in our study are the main limitations of our study. In view of cost constraints, only two (9.2\%) patients received rituximab.

\section{Conclusion}

In spite of small number of patients reported in this study, conventional chemotherapy with radiation remains an effective treatment option for patients with PBL. OS was found to be affected by the initial response to treatment. However, prospective studies are needed that will help clarify many aspects of the disease.

\section{Funding}

None.

\section{Conflicts of Interest}

There are no conflicts of interest.

\section{References}

1 Dubey P, Ha CS, Besa PC, et al. Localized primary malignant lymphoma of bone. Int $\mathrm{J}$ Radiat Oncol Biol Phys 1997;37(5):1087-1093

2 Jaffe ES. The 2008 WHO classification of lymphomas: implications for clinical practice and translational research. Hematology (Am Soc Hematol Educ Program) 2009;1:523-531

3 Baar J, Burkes RL, Gospodarowicz M. Primary non-Hodgkin's lymphoma of bone. Semin Oncol 1999;26(3):270-275

4 Kim SY, Shin DY, Lee SS, et al. Clinical characteristics and outcomes of primary bone lymphoma in Korea. Korean J Hematol 2012;47(3):213-218

5 Ramadan KM, Shenkier T, Sehn LH, Gascoyne RD, Connors JM. A clinicopathological retrospective study of 131 patients with primary bone lymphoma: a population-based study of successively treated cohorts from the British Columbia Cancer Agency. Ann Oncol 2007;18(1):129-135

6 Cheson BD, Horning SJ, Coiffier B, et al; NCI Sponsored International Working Group. Report of an international workshop to standardize response criteria for non-Hodgkin's lymphomas. J Clin Oncol 1999;17(4):1244

7 Mikhaeel NG. Primary bone lymphoma. Clin Oncol (R Coll Radiol) 2012;24(5):366-370

8 Jawad MU, Schneiderbauer MM, Min ES, Cheung MC, Koniaris LG, Scully SP. Primary lymphoma of bone in adult patients. Cancer 2010;116(4):871-879

9 Matikas A, Briasoulis A, Tzannou I, et al. Primary bone lymphoma: a retrospective analysis of 22 patients treated in a single tertiary center. Acta Haematol 2013;130(4):291-296

10 Maruyama D, Watanabe T, Beppu Y, et al. Primary bone lymphoma: a new and detailed characterization of 28 patients in a single-institution study. Jpn J Clin Oncol 2007;37(3):216-223

11 Ueda T, Aozasa K, Ohsawa M, et al. Malignant lymphomas of bone in Japan. Cancer 1989;64(11):2387-2392

12 Heyning FH, Hogendoorn PC, Kramer MH, et al. Primary non-Hodgkin's lymphoma of bone: a clinicopathological investigation of 60 cases. Leukemia 1999;13(12):2094-2098

13 Zinzani PL, Carrillo G, Ascani S, et al. Primary bone lymphoma: experience with 52 patients. Haematologica 2003;88(3):280-285

14 Beal K, Allen L, Yahalom J. Primary bone lymphoma: treatment results and prognostic factors with long-term follow-up of 82 patients. Cancer 2006;106(12):2652-2656

15 Alencar A, Pitcher D, Byrne G, Lossos IS. Primary bone lymphoma-the University of Miami experience. Leuk Lymphoma 2010;51(1):39-49

16 Pellegrini C, Gandolfi L, Quirini F, et al. Primary bone lymphoma: evaluation of chemoimmunotherapy as frontline treatment in 21 patients. Clin Lymphoma Myeloma Leuk 2011;11(4):321-325 